http://jmscr.igmpublication.org/home/ ISSN (e)-2347-176x ISSN (p) 2455-0450

crossref DOI: https://dx.doi.org/10.18535/jmscr/v8i7.68

Journal Of Medical Science And Clinical Research

IGM Publication

An Official Publication of IGM Publication

\title{
Prevalence of Depression among Epilepsy Patients in a Tertiary Care Hospital of North-East Region
}

\author{
Authors \\ Dr Atul Debbarma ${ }^{1^{*}}$, Dr Bappaditya Roy $^{2}$, Dr Siddhartha Debbarma ${ }^{3}$ \\ ${ }^{1}$ Assistant Professor, Agartala Govt. Medical College \\ ${ }^{2}$ Post Graduate trainee, Agartala Govt. Medical College \\ ${ }^{3}$ M.D, Assistant Professor of Psychiatry, AGMC \\ *Corresponding Author \\ Dr Atul Debbarma \\ Assistant Professor Agartala Govt. Medical College, Agartala, India
}

\begin{abstract}
Introduction: Epilepsy describes a condition in which a person has recurrent seizures due to chronic, underlying process. The definition implies that a person with a single seizure or recurrent seizures due to correctable or avoidable circumstances does not necessarily have epilepsy. Using the definition of epilepsy as two or more unprovoked seizures, the incidence of epilepsy is approximately $0.3-0.5 \%$ in different populations throughout the world and the prevalence of epilepsy has been estimated at $5-10$ persons per $1000^{(1)}$. Epilepsy is a common neurological disorder that affects populations worldwide and leads to severe personal, familial and social impact.

The word epilepsy is derived from Greek and means to "seize upon" or "taking hold of". Epilepsy describes a condition in which a person has a tendency for recurrent, usually unprovoked seizures due to chronic, underlying process. One of the first descriptions of epileptic seizures can be traced back to 2000 years in ancient texts from Mesopotamia. Hippocrates studied the disease and disputed its divine origin in his classic treatise On The Sacred Disease.

Aim of the Study: This study aims to find out the prevalence of depression among epilepsy patients in a tertiary care hospital of north-east region.

Materials and Methods: It was cross sectional study done on 100 patients attended to psychiatry OPD and referred from medicine OPD / IPD of AGMC \& GBP Hospital, Agartala between January 2016 to December 2016.

Result: Out of these 100 epilepsy patient in the age group of 12 to 60 years shows $50 \%$ were having depression. Moreover out of these 100 patients 29\% had mild depression, 13\% had moderate depression and $8 \%$ had severe depression. Most of the study subjects have the epilepsy since their ages between 12 to 28 years (39\%) followed by 29 to 44 years (37\%)

Most important this study shows out of these 100 patients male (54\%) followed by female (46\%). Surprisingly out of these 100 patients $37 \%$ were from upper middle class, $8 \%$ from lower middle class followed by $13 \%$ from upper lower class and 5\% from upper class. Moreover $59 \%$ patients were married followed by unmarried $41 \%$.

This study also reflect that $65 \%$ patients come from nuclear family followed by $35 \%$ from joint family. Ultimately the result of the study conclude that $41 \%$ patients had generalised tonic clonic seizure followed by followed by complex partial seizure (26\%) and absence seizure (24\%). Simple partial seizure is 5\% and
\end{abstract}


partial seizure with secondary generalization is 4\% and out of these 100 epileptic patient depression persist in 50 patient and among these 50 patients. Among 50 patients, depression in generalized tonic clonic seizure (20) is more than complex partial seizure (18) followed by absence seizure (7).

Discussion: In this study, data analysis revealed that the prevalence of depression among epileptic patients was $50 \%$ of all 100 epileptic subjects, divided between 29\% have mild depression, 13\% have moderate depression, and $8 \%$ have severe depression. The prevalence of depression among epileptic patients is variable in the previous studies, from as low as (9.5\%) as shown in the study of Pooya \& Sperlin ${ }^{(47)}$, to as high as $(61 \%)$ as shown in the study of Yousafzai et al. ${ }^{(44)}$

In my study finding about 50\% of our patients had depression, in spite of high prevalence in comparison with some previous studies. Differences of the prevalence of depression may be because of methodological differences and may be due to associated socio-economic factors in our society.

\section{Introduction}

Epilepsy describes a condition in which a person has recurrent seizures due to chronic, underlying process. The definition implies that a person with a single seizure or recurrent seizures due to correctable or avoidable circumstances does not necessarily have epilepsy. Using the definition of epilepsy as two or more unprovoked seizures, the incidence of epilepsy is approximately $0.3-0.5$ $\%$ in different populations throughout the world and the prevalence of epilepsy has been estimated at $5-10$ persons per $1000^{(1)}$. Epilepsy is a common neurological disorder that affects populations worldwide and leads to severe personal, familial and social impact.

The word epilepsy is derived from Greek and means to "seize upon" or "taking hold of". Epilepsy describes a condition in which a person has a tendency for recurrent, usually unprovoked seizures due to chronic, underlying process. One of the first descriptions of epileptic seizures can be traced back to 2000 years in ancient texts from Mesopotamia. Hippocrates studied the disease and disputed its divine origin in his classic treatise on the sacred Disease.

\section{Aim of the Study}

This study aims to find out the prevalence of depression among epilepsy patients in a tertiary care hospital of north-east region.

\section{Materials and Method}

It was cross sectional study done on 100 patients attended to psychiatry OPD and referred from medicine OPD / IPD of AGMC \& GBP Hospital,
Agartala between January 2016 to December 2016.

\section{Inclusion Criteria}

- Who have given informed consent for this study.

- All types of epilepsy cases between the age group of 12 years to 60 years irrespective of sex and socio-demographic status.

- Cases must have confirmed diagnosis of epilepsy for at least six months.

\section{Exclusion Criteria}

- Patients who have not given informed consent.

- Patient's age below 12 years and age above 60 years.

- Patients suffering from any other medical condition during the last one month period before interview were excluded from the study.

- Patients with severe mental retardation.

- Patients with history of alcohol or other substance abuse.

- Patients with status epilepticus.

- Patients having history of mood disorders prior to the onset of epilepsy.

\section{Assessment Tools}

- Epilepsy diagnostic criteria

- Socio-demographic variables

- Epilepsy related variables

- ICD-10 criteria for diagnosis of depressive disorder

- BDI (Beck Depression Inventory) scale 


\section{JMSCR Vol||08||Issue ||07||Page 430-436||July}

\section{Analysis of Data}

The data were analysed by using SPSS-15. Cross tabulation and Chi square statistics were applied to assess the association between variables. $\mathrm{P}$ value $<0.05$ was deemed as Significant. Descriptive studies were expressed in frequencies and percentages.

Table1: Showing that, amongst 100 epileptic patients 50\% were having depression.

\begin{tabular}{l} 
Prevalence of Depression \\
\hline Present \\
\hline Absent \\
\hline Total \\
\hline
\end{tabular}

\begin{tabular}{|c|c|}
\hline Frequency $(\mathrm{N})$ & Percent $(\%)$ \\
\hline $\mathbf{5 0}$ & $\mathbf{5 0 \%}$ \\
\hline $\mathbf{5 0}$ & $\mathbf{5 0 \%}$ \\
\hline $\mathbf{1 0 0}$ & $\mathbf{1 0 0 \%}$ \\
\hline
\end{tabular}

Table 2: Distribution according to severity of depression

\begin{tabular}{|l|c|c|}
\hline Severity of depression & Frequency(N) & Percent (\%) \\
\hline Mild & $\mathbf{2 9}$ & $\mathbf{2 9 \%}$ \\
\hline Moderate & $\mathbf{1 3}$ & $\mathbf{1 3 \%}$ \\
\hline Severe & $\mathbf{8}$ & $\mathbf{8 \%}$ \\
\hline Nil & $\mathbf{5 0}$ & $\mathbf{5 0 \%}$ \\
\hline Total & $\mathbf{1 0 0}$ & $\mathbf{1 0 0 \%}$ \\
\hline
\end{tabular}

Table no. 2 shows that among 100 epileptic patients $29 \%$ had mild depression, $13 \%$ had moderate depression and $8 \%$ had severe depression.

Table 3: Age distribution ofthe study population

\begin{tabular}{|l|c|c|}
\hline & Frequency(N) & Percent $(\%)$ \\
\hline $12-28$ years & 39 & $39 \%$ \\
\hline 29- 44 years & 37 & $37 \%$ \\
\hline T5- 60 years & 24 & $24 \%$ \\
\hline TOTAL & 100 & $100 \%$ \\
\hline
\end{tabular}

Table no. 3 showing that most of the study subjects have the epilepsy since their ages were between $12-28$ years $(39 \%)$ followed by $29-44$ years $(37 \%)$. Mean age of the study population is 34.13 years \pm 12.88 years (minimum age 14 years and maximum age 54 years).

Table 4: Sex distribution of the study population

\begin{tabular}{|l|c|c|}
\hline Sex distribution & Frequency(N) & Percent (\%) \\
\hline Male & $\mathbf{5 4}$ & $\mathbf{5 4 \%}$ \\
\hline Female & $\mathbf{4 6}$ & $\mathbf{4 6 \%}$ \\
\hline Total & $\mathbf{1 0 0}$ & $\mathbf{1 0 0 \%}$ \\
\hline
\end{tabular}

Table no. 4 showing that among 100 epileptic subjects most of the subjects were male (54\%) followed by female $(46 \%)$.

Table 5: Distribution according to their Socio-economic status

\begin{tabular}{|l|c|c|}
\hline Socio-economic status & Frequency(N) & Percent(\%) \\
\hline Lower Middle Class & $\mathbf{3 7}$ & $\mathbf{3 7 \%}$ \\
\hline Upper Middle Class & $\mathbf{3 7}$ & $\mathbf{3 7 \%}$ \\
\hline Upper Lower Class & 13 & $\mathbf{1 3 \%}$ \\
\hline Lower Class & $\mathbf{8}$ & $\mathbf{8 \%}$ \\
\hline Upper Class & $\mathbf{5}$ & $\mathbf{5 \%}$ \\
\hline Total & $\mathbf{1 0 0}$ & $\mathbf{1 0 0 \%}$ \\
\hline
\end{tabular}


Table 5 shows among 100 subjects with epilepsy 37\% subjects were from Upper middle class and lower middle class followed by upper lower class (13\%). Lower class (8\%) more than upper class (5\%).

Table 6: Showing distribution of epileptic patients according to marital status.

\begin{tabular}{|l|c|c|}
\hline Marital status & Frequency(N) & Percent (\%) \\
\hline Married & 59 & $59 \%$ \\
\hline Unmarried & 41 & $41 \%$ \\
\hline Total & 100 & $100 \%$ \\
\hline
\end{tabular}

Table 6 showing that among 100 epileptic subjects most of the patients were married (59\%) followed by unmarried (41\%).

Table 7: Distribution according to the type of epilepsy

\begin{tabular}{|l|c|c|}
\hline Types of Epilepsy & Frequency(N) & Percent (\%) \\
\hline Generalized tonic clonic seizure & $\mathbf{4 1}$ & $\mathbf{4 1 \%}$ \\
\hline Complex partial seizure & $\mathbf{2 6}$ & $\mathbf{2 6 \%}$ \\
\hline Absence seizure & $\mathbf{2 4}$ & $\mathbf{2 4 \%}$ \\
\hline Simple partial seizure & $\mathbf{5}$ & $\mathbf{5 \%}$ \\
\hline $\begin{array}{l}\text { Partial with secondary } \\
\text { generalization }\end{array}$ & 4 & $\mathbf{4 \%}$ \\
\hline Total & $\mathbf{1 0 0}$ & $\mathbf{1 0 0 \%}$ \\
\hline
\end{tabular}

Table no. 7 shows the types of the epilepsy found in the study group. In this study, among 100 epileptic subjects most no. of the subjects had Generalized Tonic Clonic Seizure (41\%) followed by complex partial seizure $(26 \%)$ and absence seizure (24\%). Simple partial seizure is 5\% and partial seizure with secondary generalization is $4 \%$.

Table 8: Depression in different types of epilepsy

\begin{tabular}{|l|c|c|c|c|c|c|}
\hline Depression & $\begin{array}{c}\text { Generalized } \\
\text { Tonic Clonic } \\
\text { Seizure }\end{array}$ & $\begin{array}{c}\text { Absence } \\
\text { Seizure }\end{array}$ & $\begin{array}{c}\text { Complex } \\
\text { Partial } \\
\text { Seizure }\end{array}$ & $\begin{array}{c}\text { Simple } \\
\text { Partial } \\
\text { Seizure }\end{array}$ & $\begin{array}{c}\text { Partial Seizure } \\
\text { with Secondary } \\
\text { Generalization }\end{array}$ & \begin{tabular}{c} 
Total \\
\hline Present
\end{tabular} \\
\hline Absent & $\mathbf{2 0}$ & $\mathbf{7}$ & $\mathbf{1 8}$ & $\mathbf{2}$ & $\mathbf{3}$ & $\mathbf{5 0}$ \\
\hline Total & $\mathbf{2 1}$ & $\mathbf{1 7}$ & $\mathbf{8}$ & $\mathbf{3}$ & $\mathbf{1}$ & $\mathbf{5 0}$ \\
\hline
\end{tabular}

Table no.8 shows that among total 100 epileptic patients depression is present in 50 patients. Among 50 patients, depression in generalized tonic clonic seizure (20) is more than complex partial seizure (18) followed by absence seizure (7).

\section{Discussion}

This is a cross sectional descriptive study, aimed to understand depression among epileptic patients from its prevalence and its relationship with other variables. Study was carried out on 100 epilepsy patients referred from Neurology clinics of Medicine dept. and patients from psychiatry OPD. The study was approved by Tripura University (Central) and informed consent was obtained from each of the study participants. Patients younger than 12 and older than 60 years of age, and patients suffering from other medical or psychiatric disorders were not included in the study. In this study, ICD10 diagnostic criterion was used to diagnose the presence of depression. The Beck questionnaires consisting of 21 items of multiple-choice questions with increasing severity of depression were given to the patients having depression and they were asked to answer the questions independently (self-report).

In this study, data analysis revealed that the prevalence of depression among epileptic patients was $50 \%$ of all 100 epileptic subjects, divided between $29 \%$ have mild depression, $13 \%$ have moderate depression, and $8 \%$ have severe 
depression. The prevalence of depression among epileptic patients is variable in the previous studies, from as low as $(9.5 \%)$ as shown in the study of Pooya \& Sperlin ${ }^{(47)}$, to as high as $(61 \%)$ as shown in the study of Yousafzai et al. ${ }^{(44)}$ In my study finding about $50 \%$ of our patients had depression, in spite of high prevalence in comparison with some previous studies.

Differences of the prevalence of depression may be because of methodological differences and may be due to associated socio-economic factors in our society.

\section{References}

1. Standard Text Book of HARRISONS, Principles of INTERNAL MEDICINE $18^{\text {th }}$ Edition, vol.no2, Chapter 369, page o.3251, Section 2 Diseases of the Central Nervous System.

2. W. a. M. swinkels, J. Kuyk, r. van dyck, and p. spinhoven, "psychiatric co morbidity in epilepsy," epilepsy \& Behaviour, vol. 7, no. 1, pp. 37-50, 2005.

3. S. J. Adams, t. J. O'Brien, J. Lloyd, c. J. Kilpatrick, M. r. salzberg, and d. Velakoulis, neuropsychiatric morbidity in focal epilepsy," the British Journal of psychiatry, vol. 192 , no. 6 , pp. 464-469, 2008.

4. V. sanchez-Gistau, 1. pintor, G. sugranyes, et al., "Prevalence of interictal psychiatric disorders in patients with refractory temporal and extratemporal lobe epilepsy in spain.a comparative study," epilepsia, vol. 51, no. 7, pp. 1309-1313, 2010.

5. Seminario NA, Farias ST, Jorgensen J, Bourgeois JA, Seyal M. Determination of prevalence of depression in an epilepsy clinic using DSM-IV based self- report questionnaire. Epilepsy Behav 2009; 15:362-6.

6. Kanner AM. Depression in epilepsy: A review of multiple facets of their close relation. Neurol Clin 2009; 27:865-80.
7. Adewuya AO, Oseni SB. Impact of psychiatric morbidity on parent rated quality of life in Nigerian adolescents with epilepsy. Epilepsy Behav 2005; 7:497-501

8. Kanner AM, Palac S. Depression in epilepsy: A common but often unrecognized co-morbid malady. Epilepsy Behav 2000; 1:37-51

9. Okubadejo NU, Danesi MA, Aina OF, Ojini FI, Adeyemi JD, Olorunshola DA. Prospective case -control study of interictal depression and suicidal ideation in Nigerians with epilepsy. Niger Postgrad Med J 2007; 14:204-8.

10. Boylan LS, Flint LA, Labovitz DL, Jackson SC, Starner K, Devinsky O. Depression but not epilepsy predicts quality of life in treatment resistant epilepsy. Neurology 2004; 62:258-61.

11. Forsgren L, Nystrom L. An incident case referent study of epileptic seizures in adults. Epilepsy Res 1990; 6:66-81.

12. Hesdorffer DC, Hauser WA, Annegers JF, Cascino G. Major depression is a risk factor for seizures in older adults. Ann Neurol 2000; 47:246-9.

13. Study of Lowenstein DH, 1993.

14. Study of Merlis 1974.

15. Ahuja and Mahanta, 1982; Ramirez et al., 1984.

16. Seminario NA, Farias ST, Jorgensen J, Bourgeois JA, Seyal M. Determination of prevalence of depression in an epilepsy clinic using DSM-IV based self- report questionnaire. Epilepsy Behav 2009; 15:362-6.

17. Kanner AM. Depression in epilepsy: A review of multiple facets of their close relation. NeurolClin 2009; 27:865-80.

18. Adewuya AO, Oseni SB. Impact of psychiatric morbidity on parent rated quality of life in Nigerian adolescents with epilepsy. Epilepsy Behav 2005; 7:497-501.

19. Kanner AM, Palac S. Depression in epilepsy: A common but often 
unrecognized co-morbid malady. Epilepsy Behav 2000; 1:37-51.

20. Okubadejo NU, Danesi MA, Aina OF, Ojini FI, Adeyemi JD, Olorunshola DA. Prospective case - control study of interictal depression and suicidal ideation in Nigerians with epilepsy. Niger Postgrad Med J 2007; 14:204-8.

21. Boylan LS, Flint LA, Labovitz DL, Jackson SC, Starner K, Devinsky O. Depression but not epilepsy predicts quality of life in treatment resistant epilepsy. Neurology 2004; 62:258-61.

22. Forsgren L, Nystrom L. An incident case referent study of epileptic seizures in adults. Epilepsy Res 1990; 6:66-81.

23. Hesdorffer DC, Hauser WA, Annegers JF, Cascino G. Major depression is a risk factor for seizures in older adults. Ann Neurol 2000; 47:246-9.

24. Nubukpo P, Houinato D, Preux PM, Avode G, Clement JP. Anxiety and depression among the epileptics in general population in Benin (Western Africa).Encephale 2004; 30:214-9.

25. Olley BO, Osinowo HO, Brieger WR. Psycho-educational therapy among Nigerian adult patients with epilepsy. Patient Educ Couns 2001; 42:25-33.

26. Lee SA, Lee SM, No YJ. Factors contributing to depression in patients with epilepsy. Epilepsia 2010; 51:1305-8.

27. Cramers JA, Blum D, Reed M, Fanning K. The influence of co morbid depression on quality of life for people with epilepsy.Epilepsy behav 2003; 4: 515 521.

28. Perrine K, Hermann BP, Meador KJ, Vickrey $\mathrm{BG}$, et al. The relationship of neuropsychological functioning to quality of life of epilepsy.Arch Neurol 1995; 52: $997-1003$.

29. Johnson EK, Jones JE, Seidenberg M, Hennann BP. The relative impact of anxiety, depression and clinical seizures features on health related quality of life in epilepsy. Episepsia 2004; 45: 544 - 550.

30. Cramer JA, Blum D, Fanning K, Reed M. The impact of co morbid depression on health resource utilization in a community sample of people with epilepsy. Epilepsy Behaviour 2004; 5: 337 - 342.

31. Jacoby A, Baker GA, Steen N, et al., Epilepsia, 1996;37:148-61.

32. V Seshadri, J Thomas, and JMK Murthy, CR Raju study on Prevalence of depression and its effect on quality of life in patients with epilepsy (Hyderabad, India). Neurology Asia 2004; 9 (Supplement 1): 139.

33. Study of Astejada et al. in Philippine, 2004.

34. Lopez-Gomez et al. study in Mexico 2005.

35. Grabowska-Grzybetal.studyin Poland 2005.

36. Study of Hayat Khan \& Tahir 2005, major depression risk factors in epilepsy patients.

37. Study of Nidhinandana et al., study to determine prevalence of depression among epileptic patients in Phramongkutklao Hospital.2007.

38. Kanitpong et al. (2007), study of prevalence of depression and anxiety in Thai epileptic patients at Songklanagarind Hospital by using cross sectional design.

39. Delhi psychiatry journal vol. 12 no.L.2009.

40. Study of Zahiroddin et al.(2008) in Iran, study of prevalence of depression in epilepsy patients.

41. Study of Thomson \& Brennenstuhl (2009) in Canada.

42. Neurology teaching hospital, P.M.B.01129 ENUGU, Nigeria 2009.

43. Aziz-Ur-RehmanYousafzai, Abdul Wahab Yousafzai, Rizwan Tajstudy on Frequency Of Depression In Epilepsy: A Hospital Based Study 2009.

44. Oliveira et al. (2010) in Brazil, study of frequency and intensity of psychiatric 
disorders in a group of temporal lobe epilepsy patients from a tertiary care centre.

45. Kutlu et al. (2010) in Turkey, study on health-related quality of life (HRQOL), anxiety and depression states of patients with epilepsy.

46. Asadi-Pooya \& Sperling 2011 in USA,cross sectional study to evaluate the prevalence of anxiety and depression in epilepsy.

47. IO Onwuekwe et. al (2012)study,( 2012 jan-june,291):10-13, DOL: 10.4103/21419248.96929).

48. Study of Khalid Z amel, Toufik Alsaadi on depressive disorders in epileptic patients published at vol.5, no.6A1, 14-20(2013), DOI: 10.4234 health.2013.56A1003.

49. Prevalence and factors associated with depression among patients with epilepsy by Nikuku Kiko, 2013 thesis dissertations/578/1/2.

50. Vijay Kumar et al., (2015) study on Prevalence of Depression and Adverse drug reactions among South Indian Epileptic patients at Kovai Medical Centre and Hospital, Tamil Nadu.

51. Berhanu et. al, study of Depression on epilepsy patients in North-East Etiopia, DOI: 10.1186/s13104-015-1515-z).

\section{Abbreviations}

AEDs- Anti Epileptic Drugs, AOR- Adjusted Odd Ratio, AGMC- Agartala Government Medical College, BDI- Beck Depression Inventory, CNSCentral Nervous System, EEG- Electro Encephalography, GABA- Gamma Amino Butyric Acid, IPD - In Patient Department, ICDInternational Classification of Disease, OPD- Out Patient Department. 